\title{
Revisiting the Social Origins of Human Morality: A Constructivist Perspective on the Nature of Moral Sense-Making
}

\author{
Andrés Segovia-Cuéllar ${ }^{1}$ (D)
}

Accepted: 6 September 2021 / Published online: 11 October 2021

(c) The Author(s) 2021

\begin{abstract}
A recent turn in the cognitive sciences has deepened the attention on embodied and situated dynamics for explaining different cognitive processes such as perception, emotion, and social cognition. This has fostered an extensive interest in the social and 'intersubjective' nature of moral behavior, especially from the perspective of enactivism. In this paper, I argue that embodied and situated perspectives, enactivism in particular, nonetheless require further improvements with regards to their analysis of the social nature of human morality. In brief, enactivist proposals still do not define what features of the social-relational context, or which kind of processes within social interactions, make an evaluation or action morally relevant or distinctive from other types of social normativity. As an alternative to this proclivity, and seeking to complement the enactive perspective, I present a definition of the process of moral sense-making and offer an empirically-based ethical distinction between different domains of social knowledge in moral development. For doing so, I take insights from the constructivist tradition in moral psychology. My objective is not to radically oppose embodied and enactive alternatives but to expand the horizon of their conceptual and empirical contributions to morality research.
\end{abstract}

Keywords Moral psychology $\cdot$ Social normativity $\cdot$ Moral sense-making $\cdot$ Constructivism $\cdot$ Enactivism

\section{Introduction}

A recent turn in the cognitive sciences has deepened the interest in embodied and situated dynamics for explaining different cognitive processes such as perception, emotion, and social cognition (Varela et al. 1991/2016; Prinz 2007; Gigerenzer 2008; Thompson 2010; Chemero 2011; Stewart et al. 2014; Haidt 2013; Colombetti 2017; Shapiro 2019; Asma and Gabriel 2019). This has fostered an extensive interest in the 'intuitive' nature of our moral behavior in moral psychology and philosophy (Dreyfus and Dreyfus 1991; Varela 1999; Prinz 2006, 2007; Greene 2001, 2007; Haidt 2001, 2013). Furthermore, proponents of the enactive theory of cognition have highlighted the relevance of second-person interactions and intersubjectivity for properly explaining human morality (De Jaegher and Di Paolo 2007; Colombetti and Torrance 2009; Urban 2014, 2015;

Andrés Segovia-Cuéllar

asegovia.cc@gmail.com; andres.segovia@campus.lmu.de

1 Research Center for Neurophilosophy and Ethics of Neuroscience, Ludwig-Maximilians-Universität München, Munich, Germany van Grunsven 2018; Bergmann and Wagner 2020). From this perspective, moral judgments and moral behavior are embodied in nature, built upon emotional and automatic processes, and are always embedded in concrete socialecological contexts.

Nevertheless, these perspectives still face important challenges associated with their analysis of the social origins of human morality. In this paper, I argue that these theories leave room to further define what features of the social-relational context, or which kind of processes within social interactions, make an evaluation or action morally relevant or distinctive from other types of social normativity. More precisely, it is still unclear if these models consider the development of moral concerns and judgments as a simple matter of social conformity, or if developing, learning, and understanding a moral norm (e.g., not to harm others and respect the dignity of persons) is the same as developing, learning or understanding any norm established by a group to organize their social life (e.g., how to dress properly according to the standard of a community). In what follows I reflect on these concerns, offering a complementary perspective. My objective is not to radically oppose embodied and enactive alternatives but to expand the horizon of their 
conceptual and empirical contributions to morality research. For doing so, I take insights from the constructivist tradition in moral psychology and explore the potential articulation between this tradition and the perspective of enactivism. ${ }^{1}$

This paper has four sections. In the first section, I will briefly discuss the basic arguments of embodied and enactive approaches in morality research. In the second section, I will elaborate on an argument showing how the philosophical background of enactive proposals makes them adopt an ambiguous perspective on the social origins of morality. This ambiguity occasionally comes linked with social determinism, which demands a clearer definition of what morality is in the first place. In the third section, I expose the basic principles of the constructivist tradition in moral psychology and evaluate its potential connections with the enactive tradition. Accordingly, I explore the distinction between different domains of social knowledge during human development and present a definition of the process of moral sense-making that I consider relevant for the enactive perspective. In the final section, I extend this contribution finishing with a pertinent reflection on the role of reasoning in human morality.

\section{The 'Embodied'Turn in Moral Psychology and the Enactive Approach}

A recent turn in the cognitive sciences has deepened the interest in the intuitive nature of our moral behavior and the relevance of second-person interactions and intersubjectivity for explaining human morality (Varela 1999; Prinz 2007; Haidt 2013; Colombetti and Torrance 2009; Urban 2014, 2015; van Grunsven 2018; Bergmann and Wagner 2020). One common feature of these models is their claim about the necessity to overcome the limitations of 'rationalist' approaches in moral psychology, traditionally associated with classical evolutionary and developmental models (Piaget 1932/2013; Kohlberg 1984). In brief, it is claimed that traditional moral psychology focused exclusively on the role of individual reasoning, cognitive control, and artificial moral problems for explaining the nature of moral concerns and judgments (Varela 1999; Colombetti and Torrance 2009; Haidt 2013; van Grunsven 2018; Bergmann and Wagner 2020). This turn is the outcome of an empirical finding, namely, that human moral judgments

\footnotetext{
1 This work is focused exclusively on the tradition of constructivism in moral developmental psychology, initiated by Piaget (1932/2013), and expanded by Kohlberg (1984) and Turiel (1985). Therefore, this work makes no reference to the tradition of metaethical constructivism. Constructivism in metaethics could be traced back to the seminal revision that John Rawls made of Kantian ethics (Rawls 1980), and grounds the philosophical work of Korsgaard (2003), Street (2010) or Bagnoli (2016).
}

have consistently shown to be the result of automatic processes that just after being realized, pave the way to slow, conscious moral reasoning and justification (Haidt 2001, 2013; Prinz 2007; Gigerenzer 2008; Greene 2007).

Conversely, embodied perspectives seek to develop a plausible theory of human morality taking into consideration two main theses: the 'automaticity thesis' and the 'anti-rationalist thesis' (Sauer 2017). The 'automaticity thesis' considers the fact that moral judgments " .... are not based on critical reflection, but on uncontrolled, emotionally charged states of intuitive (dis)approval" (íbid, p. 52). The 'anti-rationalist' thesis has it that reasoning plays no significant role in morality and moral judgment since reasoning is just a subordinate process of confabulating justifications that come after the elicitation of pre-reflective and automatic intuitions. In this picture, moral reasoning is a kind of "post-hoc" justification that supports intuitive judgments (Haidt 2013). ${ }^{2}$

However, embodied approaches diverge despite their convergence in the adoption of the automaticity and the antirationalist theses, especially concerning the origins of our moral intuitions and their degree of flexibility (Bergmann and Wagner 2020). For instance, some authors from the fields of social and cognitive psychology have defended a vision in which moral embodied intuitions are evolutionary adaptations and innate mechanisms that evolved as inflexible reactions to features of the social environment. In the social intuitionist model and the 'moral foundations' theory proposed by Haidt (2013), morality is the result of innate dispositions of the human species and supposes the natural outcome of different domain-specific adaptations, which evolved in ancestral scenarios of cooperative interaction to solve certain social and cooperative challenges (Graham et al. 2013). These moral intuitions are triggered by stimuli from the social environment and are the object of cultural modulation during development (Haidt and Bjorklund 2008, p. 206).

The 'Evolutionary Developmental Model' (EDM) of human morality recently proposed by Buchanan and Powell (2018), is also an example of a naturalistic theory that explains morality along with the evolution of adaptive intuitions shaped by specific features of the human social

\footnotetext{
${ }^{2}$ Such an embodied approach to morality is already present in the proposals of classical philosophers, in the west and the eastern tradition, who proposed that human reasoning is just a slave of the passions and that we are always embedded in habitual behaviors that do not need a constant cognitive control or reasoned planning. Accordingly, ethical expertise would be the result of embodied, intuitive, and concrete situated processes, and not the outcome of rational deliberation and the manipulation of abstract information. This is the line of thought of 'wisdom' traditions like Confucianism, Taoism, and Buddhism (Gordon et al. 1999; Varela 1999; Shun and Wong 2004; McCarthy 2010), and also the view of morality proposed by the Scottish enlightenment philosophers (Hutcheson 1725/2014; Smith 1759/2010).
} 
environment. According to the EDM, human morality evolved as an adaptively plastic trait since it shows different patterns of 'exclusivist' and 'inclusivist' tendencies depending on the presence of certain features in the social environment. ${ }^{3}$ For instance, the expression of exclusivist moral tendencies (e.g., parochial prosociality, intergroup competition, ingroup bias) would be an automatic response triggered by the presence of certain environmental features in the developmental niche of human individuals, that would resemble the ancestral environments of human evolution: the presence of 'out-group threat, competition for resources, or disease transmission (Buchanan and Powell 2018). On the other hand, inclusivist tendencies would emerge when the environmental features that usually trigger exclusivist responses are absent. ${ }^{4}$

From an arguably different embodied perspective, the enactive tradition has proposed that human morality requires what might be called 'ethical know-how' or the expertise of those individuals who intuitively know how to act in a given morally relevant situation. The enactive approach proposes that cognitive agents do not represent and process information from a world full of already given meaning, but 'enact' or 'bring forth' knowledge through their embodied and situated interactions with the world (Varela et al. 1991/2016). Following the ideas of Jean Piaget, pioneer enactive theorist Francisco Varela claimed that "the world is not something that is given to us but something we engage in by moving, touching, breathing, and eating. This is what I call cognition

\footnotetext{
${ }^{3}$ In the scientific and philosophical literature on the matter, exclusivist moralities refer to those based on moral concerns and motivations that are limited by the boundaries of groups and configure a parochial sense of prosociality. Inclusivist moralities, conversely, would be those that "... reject group-based restrictions on moral standing and moral status" (Buchanan and Powell 2018).

${ }^{4}$ According to this model, the emergence of inclusivist moral concerns or the possible erosion of inclusivist moralities would be the consequence of two factors: (a) the concrete physical 'presence' or 'absence' of the ancestral harsh conditions that usually trigger exclusivist responses in humans (e.g., out-group threat, competition for resources, and disease transmission), or (b) the social manipulation of beliefs, that makes people think that these features are present or absent in the environment. In the end, the expression (or suppression) of exclusivist moral tendencies are just the result of the activation of 'evolved cognitive biases' or pre-reflective intuitions and evaluations, such as the ones involved in the basic human tendency to essentialize human groups. As a consequence, Buchanan and Powell have claimed that inclusivist morality is a 'luxury good', that "it is only likely to be widespread and stable in highly favorable conditions", and that "inclusivist gains can be eroded if harsh conditions reappear or a significant number of people come to believe that they exist" (2018, p. 188).
}

as enaction since enaction connotes this bringing forth by concrete handling" (Varela 1999, p. 8). ${ }^{5}$ De Jaegher and Di Paolo (2007) have also argued that "natural cognitive systems are simply not in the business of accessing their world in order to build accurate pictures of it. They actively participate in the generation of meaning in what matters to them; they enact a world" (p. 488).

These assumptions apply to the case of human morality, for morality is based upon embodied habits that have been cultivated in concrete contexts of social interactions (Varela 1999). This is the most fundamental contribution of enactivist theories since human morality has a socially situated nature. The enactive perspective defends the idea that all human forms of cognition have a social origin. For explaining this, recent enactivist theorists have proposed the concept of 'Participatory sense-making', which is defined as "the coordination of intentional activity in interaction, whereby individual sense-making processes are affected and new domains of social sense-making can be generated that were not available to each individual on her own" (De Jaegher and Di Paolo 2007, p. 497).

Starting from the idea of participatory sense-making, the enactive tradition has focused its research on the intersubjective nature of human forms of cognition in general, and social cognition, social normativity, and ethical behavior in particular (De Jaegher and Di Paolo 2007; Colombetti and Torrance 2009; Urban 2014, 2015; van Grunsven 2018; Di Paolo et al. 2018). Accordingly, social normativity and human morality are explained as the result of 'participatory sense-making' or the process through which cognitive agents jointly generate new meanings and make sense of the world through coordinated interactions.

To sum up, certain naturalistic and philosophical models have proposed pictures of human morality based upon the relevance of embodied judgments and intuitions for the expression and realization of moral judgments and actions. These models sometimes differ in their conception about the degree of flexibility of our moral judgments. As a consequence, some versions within the movement have opted to highlight the essential role of interpersonal and social factors for moral judgments to develop in human individuals. This is the case of the enactive tradition and its focus on "participatory sense-making' processes and the intersubjective

\footnotetext{
${ }^{5}$ It surprises why Varela rejected the constructivist account of moral development that Piaget developed in 'The moral judgment of the Child' (1932). Contrary to what Varela suggests in his book 'Ethical Know-How' (1999), the study of Jean Piaget was one of the first attempts to study morality in concrete situations of social interaction, and the first to conceptualize morality as the result of an active construction derived from the social interactions that children have with their peers and parents. It is also negatively surprising that the only reference that Varela did to Piaget's work on moral development was a quote taken from the first page of his book.
} 
nature of morality. However, this 'intersubjective' or 'social' turn has led to ambiguous considerations around the social origins of moral behavior and an unclear definition of the moral domain or the process of moral sense-making. In the next section, I consider these limitations.

\section{On the Social Nature of Human Morality}

In a recent article, Bergmann and Wagner (2020) have developed a parsimonious summary of the embodied and enactivist thinking in the field of moral psychology. In this work, the authors name a 'moral fiction' the idea of reasonbased moral judgments and claim that moral actions are not the result of reasons or reason-based judgments but prereflective evaluative processes. Additionally, they attempt to complement the main shortcoming of the intuitionist and embodied models, namely, their inability to account for the flexibility of our pre-reflective judgments in the moral domain.

For instance, when describing the flexibility of the embodied pre-reflective evaluations that make moral judgments and actions possible, Bergmann and Wagner claim that "...we have specific repertoires of interaction possibilities in specific relational contexts, and, thus the concrete occurrence of an embodied judgment depends on how an agent relates to a specific state of affairs, as well as which embodied judgments this agent has cultivated in this specific relational context" (2020, p. 2).

The previous statement is pervasive in most enactivist proposals around the nature of human morality. For instance, Di Paolo et al. (2018) have stated that "the ethical stance is a practical one, a type of ethical know-how. We should think of it as a form of expertise, like riding a bicycle, with the double implication that we can be more or less ethically skillful and that our ethical attitudes are often pre-reflective" (p. 310). This is also the perspective defended by Francisco Varela, who claimed that: “...we acquire our ethical behavior in much the same way we acquire all other modes of behavior: they become transparent to us as we grow up in society. This is because learning is, as we know, circular: we learn what we are supposed to be in order to be accepted as learners. (...) it is clear that an ethical expert is nothing more or less than a full participant in a community: we are all experts because we all belong to a fully textured tradition in which we move at ease." (1999, p. 24).

As it happens alike with the concept of 'participatory sense-making' (De Jaegher and Di Paolo 2007), these sentences sound a plausible explanation of the embodied nature of human social relationships, or about how human individuals establish different domains of normativity and divergent ideas of what does it mean to live a 'right' and 'virtuous life'. However, there is no clear definition of which kinds of interaction are morally relevant from a particular ethical point of view. This makes elusive the consideration about what would differentiate, if possible, morality from other domains of social normativity. In the end, their attempts result in ambiguous considerations about the social nature of human moral psychology that demand a clearer definition of what morality is in the first place.

In the case of $B \& W$, they seem to approach the question by claiming that "the experience of the rightness of an action that drives a person to act depends on the sensorimotor interactions that have cultivated an agent's perspective on the world" (2020, p.1), that "people experience the permissibility of their actions depending on their specific repertoire of sensorimotor expertise" (ibid, p. 7), or that "a cognitively adequate ethical analysis has to focus on the appropriateness of a judgment in a relational context and the appropriateness of the relational context established" (ibid, p. 9).

However, it is not entirely clear what features of the relational context or which type of the 'sensorimotor interactions', 'participation', or 'expertise' that have cultivated a "subject's perspective of the world" would be morally relevant (or even morally correct) according to these perspectives. In what follows, I will try to persuade the reader to agree on why embodied and enactive theories in moral psychology should be more concerned with the adoption of a clearer definition of moral normativity, at least if they attempt to contribute to current debates in normative ethics. To make this clear, consider these different ethically relevant actions that owed to the sensorimotor interactions, expertise, and narratives that have cultivated a 'subject's perspective of the world', might be considered "permissible" or "appropriate" to perform in a given context.

(1) A young adult living in a poor neighborhood of a capital city kills someone to steal their mobile phone.

(2) A crowd of people lynches the murderer involved in action one.

(3) A group of adolescents steals a wallet from a person who is not taking care of their belongings.

(4) In a community, women are condemned to punishment and isolation when they menstruate.

All these are instances of morally relevant actions if we adopt a definition of moral action as an action that is considered appropriate or permissible in a concrete context of interpersonal and communitarian relations. For instance, following the premises of the social intuitionist model of Jonathan Haidt (2013), all these actions could be interpreted as belonging to the human moral domain since they are practices that can be considered both right-appropriate or wronginappropriate in concrete relational contexts where our adaptive intuitions (e.g., fairness, loyalty, authority, purity) have 
been cultivated through particular forms of "assisted externalization" (Haidt and Bjorklund 2008, p. 206).

Strictly following the terms of some enactivist proposals, these actions might be considered 'permissible' or 'appropriate' according to different worldviews that persons might have cultivated through their sensorimotor interactions and social expertise. In the first case, from the perspective of a young adult individual who grew up in an extremely unequal and violent context of a capital city, it may feel appropriate to kill someone to steal a mobile phone, as a way to restore social injustice. In the second case, given the increase of insecurity and hostility in the city where the young criminal lives, a huge group of citizens increasingly support the idea that thieves and murderers do not deserve to live and consider it permissible and appropriate to torture or kill these criminals to prevent future crimes. In the third case, a group of adolescents has cultivated a worldview according to which a person is justified to take advantage of other persons if they give you the chance to do so. The fourth case just exemplifies the violation of basic human rights in the name of a concrete religious or ethnic tradition.

Nonetheless, if we assume that any act considered appropriate or correct in a certain relational context belongs to the domain of morality -for instance, those related with 'obedience', 'divinity' or 'purity' according to the model of Haidt-, "...we would have no criteria for calling into question the moral validity of any rule offered as divine" (Nucci 2016, p. 293). In the end, as an example, the capture, enslavement, rape, or killing of people for religious reasons, would not be the object of condemnation if we assume that they are the concretization of genuine moral intuitions and the product of relational contexts in which these intuitions are embedded.

At this point, it is fair to question if, for most embodied and enactive approaches, learning and developing a social norm or a socially cultivated behavior is equivalent to learning or developing a moral concern, judgment, or norm. Following the distinction of Hindriks and Sauer (2020), enactivist approaches seem to have been worried about the domain of ethics, this is the values, norms, and ideals that are worthy of adoption and adherence in a given community depending on how they conceive of the good life (Scanlon 1998; Hindriks and Sauer 2020, p. 10). However, there is an absence of a clear narrative about how our moral concerns could be distinguished from other forms of social normativity.

This is not an unfounded concern, for most embodied and enactivist perspectives discussed so far sympathize with 'communitarian' approaches in political philosophy, in western (MacIntyre 1981/2014; Taylor 1989), and eastern traditions (Yearley 1990; Varela 1999). These communitarian approaches endorse a collectivistic narrative that arguably calls attention to the relevance of conformity, obedience, and attachment to social and conventional normativity in the development of morality, as a way to react to the 'atomistic', 'individualistic' and 'disembodied' perspective of liberal political philosophy and the ideology of the western culture.

For instance, according to Haidt (2013), the science of human morality in the west suffers from a 'rationalist delusion' that narrowed down the moral domain to an issue of 'well-being' and 'justice', individualistic cultural values of the "liberal western world". A morality just based on the principles of care and fairness, Haidt claims, is a WEIRD morality exclusive to "western, educated, industrialized, rich, and democratic" contemporary societies. Haidt's critique is based on the idea of 'three moralities' of 'autonomy', 'community', and 'divinity' proposed by Richard Shweder (Shweder et al. 1997) who was himself a supporter of the communitarian approach of MacIntyre (1981).

Shweder is also well-known for his critiques of the constructivist tradition proposed by Lawrence Kohlberg (1981) since for Kohlberg, he expressed, "the history of the world and the history of childhood (in all societies) is the story of the progressive discovery of the principles of the American Revolution" (1982, p. 421). Furthermore, based on the work of MacIntyre, Shweder claims that "the modern secular individualist, having lost his concept of the ends (the telos) of life and having conceived of the self as either prior to or outside society and community, is left with no fixed reference point for constructing a rational moral code" (1982, p. 422).

Some enactivist approaches to morality and ethics have explicitly expressed a theoretical sympathy with the communitarian assumptions of these theorists, particularly MacIntyre (1981), Taylor (1989), the Confucianist tradition (Yearley 1990), and more recently Haidt (2013). This is particularly explicit in the seminal work of Varela (1999), and also in subsequent approaches, the most recent being Bergmann and Wagner (2020).

Naturally, most of embodied and enactive perspectives identified with these statements should reply by saying that their main philosophical and scientific objective is just to describe morality according to what people consider as morally relevant in historically-sensitive social interactions, and not to inquire about what morality is (or ought to be), or what we ought to do. However, a social situationist perspective is not a normative impartial ethical theory if it says nothing about what distinguishes the moral domain from other domains of social normativity, or leaves unexplained the relevance of individuality and non-conformity in the configuration of justifiable moral concerns and evaluations (Killen 2018, p. 769).

As an alternative to this proclivity, and seeking to complement the enactive perspective, I claim that it is useful to clarify further what defines morality in the first place and what distinguishes moral normativity from other domains of social normativity. To do so, I will explore the potential contributions of the constructivist tradition in moral psychology, which defines morality based on normative individualism 
or the idea that persons are the ultimate units of moral concern (Beitz 1999; Jones 1999). A descriptive perspective based on normative individualism is not incompatible at the explanatory level with the role of interpersonal bonds or social interactions in moral development and learning. Some proposals within the enactive tradition have even inquired around this matter, starting a fruitful articulation between enactivism and the ethics of care (de Jaegher 2013; Urban 2014, 2015; van Grunsven 2018; Loaiza 2019; Métais and Villalobos 2021).

The next section is dedicated to exploring the articulation of enactivist ideas with the constructivist tradition in the study of moral development. This tradition has been considered the 'rationalist' and 'atomistic' stance in moral psychology par excellence. However, I will show how it perfectly complements enactive accounts offering a concrete definition of the domain of moral normativity and explaining the development of moral concerns and judgments during ontogeny. This is crucial, for it establishes the background for an empirically grounded enactive conception of moral sense-making. The adoption of some of the ideas of the constructivist tradition is essential for enactive perspectives to properly address conceptual and descriptive challenges to their perspectives.

\section{Defining the Moral Domain and the Process of Moral Sense-Making}

Some authors within the 'enactive tradition' have recently defended the convergence of enactivism with the tradition of 'care ethics' (Gilligan 1982/2006; Noddings 2013; Tronto 1993; Held 2007). According to this line of thinking, the domain of moral concerns and norms should be found in the processes of 'caring' and 'respecting' the well-being, needs, and vulnerabilities of persons. Such a description certainly helps to distinguish the development, learning, and understanding of morally relevant concerns or norms from the development, learning, and understanding of non-morally relevant social normativity.

It is at this point where the constructivist perspective in moral developmental psychology offers a relevant source of theoretical insights and empirical evidence to the enactivist, especially for explaining the process of moral development, or moral sense-making. The constructivist tradition (i) especially elaborates a meaningful definition of morality as a domain of concerns, judgments, and norms that specifies how we ought to treat others in social interactions, (ii) offers a clarification of the relationship between the affective domain and a particular view of human rationality, and (iii) contributes to an overall non-reductionist perspective that eschews erroneous dichotomies between nature and nurture, intuition and reasoning, and self and community.
To begin with, from a constructivist perspective, moral concerns, judgments, and norms are neither the result of the expression of innate adaptive intuitions nor the product of social conformity and a simple process of mirroring the normativity that communities have established to organize their social life. Instead, human individuals construct moral concerns and judgments during social interactions (Piaget 1932/2013, 1977/2015; Damon 1977; Kohlberg 1981, 1984; Turiel 1985; Smetana 1984, 1989; Carpendale et al. 2013; Carpendale and Hammond 2016; Dahl et al. 2017; Dahl and Killen 2018a, b; Dahl and Paulus 2018; Dahl 2019). ${ }^{6}$

This idea of morality as constructed in social interactions complements the focus of enactivism in the second-personal origins of morality and is also perfectly complemented by the definition of social interactions according to enactivism. Therefore, social interactions are conceptualized here "...not merely (as) places where the individual and cognitive meet the social and cultural. Social interactions, and the practices they underpin, are the kiln where both culture and cognition are forged; they are a source, ${ }^{7}$ not a meeting point" (Di Paolo et al. 2018, p. 133).

The central story in the study of morality is, therefore, how morality develops during early childhood through social interactions, and how children develop an understanding of morality as a distinctive form of social knowledge (Smetana et al. 2018). Contrary to this idea, innatist alternatives in developmental psychology have proposed that human beings come with a natural capacity to evaluate prosocial and antisocial agents, in brief, innate social preferences (Hamlin et al. 2007; Bloom 2013; Hamlin 2013). On the other hand, according to socialization theories, the development of moral concerns and judgments is just a matter of conformity (Bandura and McDonald 1963; Kochanska 1993; Day and Tappan 1996; Grusec et al. 2014). However, in socialization theories "...the child is assumed to passively adopt and follow local social norms, and thus morality is equated to conformity. Such accounts are problematic because they do not explain how moral norms initially develop. This position also entails relativism because morality is reduced to conforming to current local beliefs with no way to evaluate the moral beliefs of different collectives." (Carpendale 2009, p. 271).

The constructivist perspective is instead inspired by the classical cognitive-evolutionary approach to human development according to which the development of human

\footnotetext{
${ }^{6}$ From an arguably similar perspective, the relational approach to morality (Mascolo and DiBianca Fasoli, 2020) argues that "...moral values are neither universal reflections of a biological, social or spiritual world, nor are they relativistic creations of particular cultures or social groups or individuals. Instead, moral values and beliefs are emergent properties of relational experience" (p. 392).

7 The emphasis is mine.
} 
cognition goes beyond the imposition of biological or cultural determinations (Piaget 1932/2013, 1977/2015; Kohlberg 1981, 1984; Damon 1977; Turiel 1985; Smetana 1984, 1989; Carpendale et al. 2013; Jambon and Smetana 2014; Dahl and Killen 2018a, b; Smetana et al. 2018; Paulus 2020). From this perspective, it is necessary to evaluate when during development human children concretize normative stances which are the expression of different forms of social knowledge, including morality. These normative stances are commonly associated with affective reactions but are mostly present in explicit judgments, justifications, and behavioral interventions (e.g., protest, punishments, and rewards). These features are especially relevant, for communication and language become essential components of morality and unequivocal empirical indicators of moral stances (Kohlberg 1984; Paulus 2020; Li and Tomasello 2021). I'll be back to this point later.

However, if we want to clarify the development of moral concerns and norms of behavior as a distinctive domain of social knowledge, it is essential to define what moral normativity would be in the first place. Authors from the 'socialdomain' perspective- a branch of the cognitive-evolutionary tradition-, have consistently shown that human children develop different kinds of norms during their social interactions with parents and peers, and within them, there exist a unique set of evaluative concerns and prescriptive norms of behavior regarding how we ought to treat others and how we ought to establish personal relations promoting others' welfare, rights, fairness, and justice (Dahl and Killen 2018a, b; Turiel 2015). These concerns, evaluations, and norms would constitute the moral domain of social knowledge.

As Dahl et al. (2011) claim, “...our lives are organized around concerns. By concerns, we mean whatever is important to us, whatever we are interested in, and whatever engages us. Moral concerns constitute a subset of our concerns, namely those that are oriented to justice, rights, and welfare-in short, our concerns for the well-being of others". These evaluative concerns are configured through interpersonal relations during development and are later reflected in an individual's judgments, reasoning, protests, and emotional reactions to social events (Dahl 2019).

Based on these ideas, moral sense-making is defined here as the constructive process through which human individuals, by the means of constant interactions on a background of mutual respect and recognition, develop evaluative concerns about how we ought to treat others, and how to 'care' and 'respect' others' well-being, needs, and vulnerabilities. This process of moral sense-making is different from the process of learning social-conventional rules (e.g., concerns and norms about traditions, conventions, and narratives about group functioning), since it involves unique forms of interpersonal normativity that emerge on a background of autonomy, reciprocity, and mutual respect.
As a consequence, the moral domain is mostly experienced as "universalizing and binding" (Mascolo and DiBianca Fasoli 2020), and moral norms are assumed as prescriptive and generalizable, which means that they do not depend on the cultural context, on the defense of a particular group identity, do not rely on a figure of authority, and the commitment to these norms has no relation to avoidance of punishment (Killen 2018). This is fundamental, for heteronomous contexts in which moral norms are assumed as prescriptive just because they are imposed by an individual or social authority hinder the possibility of moral concerns to properly develop in human individuals (Piaget 1932).

The constructive process that shapes the process of moral-sense making starts in the first two years of human development (Turiel and Dahl 2019). This development is guided by an extraordinary impulse of children to be involved in the activities of adults and social interactions through genuine social motivation (Paulus 2014; Pletti et al. 2017). This social motivation could be explained as a product of our cooperative niches where human children need the attention of parents and conspecifics to survive, which leads to the development of enhanced capacities of intersubjectivity and shared intentionality (Tomasello and González-Cabrera 2017). This social motivation allows the emergence of dyadic interactions between infants and adults during the first months of life and also is causally correlated with the appearance of shared intentional scenarios and behaviors like shared attention, gaze-following, social reference, and declarative gestural communication (Tomasello 2018). Moreover, it is the primary source of positive and reciprocal family interactions, it is crucial for responding to the distress of others, and it is linked to the capacity to engage in simple instrumental helping as a form of social interaction (Brownell 2016).

A stage of pre-altruistic behaviors starts when children begin to engage in instrumental helping before reaching two years, because of their capacities for goal completion and action fulfillment (Dahl and Paulus 2018). These behaviors are the result of enhanced social understanding, which allows children to understand the actions of others and their intentions (Carpendale and Lewis 2010; Paulus 2014; Warneken and Tomasello 2007). However, until this stage, moral evaluative concerns are not yet entirely constructed or reflected in an individual's expressions or reasoning. Human children even engage in constant transgressions that involve the infliction of harm onto others (Dahl 2016; Dahl and Freda 2017; Dahl et al. 2017; Smetana et al. 2018).

It is not until the end of the second year that children start to consolidate the different domains of social knowledge through their social interactions, and develop moral, conventional, and personal concerns independently (Smetana 1984, 1989; Smetana and Braeges 1990; Smetana et al. 2018). Children start to show empathic concern for others, 
relieve others' distress, and act upon the emotional signals of harm or sadness in others, something that is the result of emotional communication and interaction during the first months of life (Zahn-Waxler et al. 1992; Dahl and Campos 2013; Dahl et al. 2011).

These concerns for the well-being of others come along with parents' encouragement and bidirectional social interactions and scaffolding (Dahl and Campos 2013; Wainryb and Recchia 2017; Dahl 2016; Dahl and Brownell 2019). For instance, some studies have found that caregivers provide domain-specific justifications in their interactions with children during the first two years of development (Smetana 1984; Dahl and Campos 2013). Moreover, the responses of parents to children's transgression are different depending on the consequences of the actions performed, or the type and content of the norm transgressed. Parents react with anger to harmful acts performed by children (morally relevant actions), with fear or worry to dangerous transgressions for the children themselves (prudential norms), and warmth or laughter to conventional rules (Dahl and Kim 2014). However, the effect of these social contingencies is not sufficient for the consolidation of the moral domain of social knowledge and it is always essential for the children to "critically evaluate" parental prohibitions (Turiel and Dahl 2019).

All these social dynamics are essential for the configuration of the moral domain and other domains of social knowledge. Around three years, children finally consolidate, apply, and endorse concerns for others' welfare, and they start to understand that harming others is morally wrong (Hardecker et al. 2016; Mammen et al. 2018; Dahl et al. 2017). The moral domain is then constituted as a set of 'strong evaluations' and prescriptive norms characterized as obligatory, generalizable, and impersonal, due to their relation with welfare, justice, and rights (Turiel 1985; Mascolo and DiBianca Fasoli 2020).

By three and four years of age, children finally reach the stage of a normative stance toward moral actions, establish a clear distinction between prescriptive moral norms and conventional rules, and also engage in reasons and judgments for evaluating the social world (Turiel 1985; Smetana et al. 2018). From this point, the differentiation of moral and conventional rules is even materialized in different physiological reactions towards instances of these norm transgressions (Yucel et al. 2020). To get to this point, children have had to consolidate their moral concerns and judgments starting from basic social-affective processes such as emotional communication and interaction, empathy, and social understanding (Dahl et al. 2011; Ball et al. 2016).

\section{Human Morality, Emotions, and Reasoning}

One of the most significant contributions of the constructivist tradition in moral psychology is precisely that morality is defined as a concrete domain of prescriptive norms of behavior based on evaluative concerns and judgments about how we ought to treat others and how to establish personal interactions promoting individual welfare, rights, fairness, and justice (Dahl and Killen 2018a). However, the development of this moral domain requires an intricate relation between affective/emotional and cognitive dimensions and the exercise of moral reasoning in and through social relations. Even though the enactive tradition has called attention to the necessity of considering emotion and cognition as integrated dimensions of the process of living organisms' sense-making of the environment (De Jaegher and Di Paolo 2007; Colombetti and Torrance 2009; Colombetti 2010, 2014) the role of reasoning and deliberation in moral development is poorly explored in these perspectives.

From an enactivist approach -as it was suggested by one of its pioneers-, human intentional deliberation and reasoning do exist in the domain of ethics and they play a role in the configuration of moral habits (Varela 1999). For instance, deliberation and analysis are important processes for the acquisition and revision of moral intuitions in moments of breakdown, this is, "when we are not experts of our microworld anymore, that we deliberate and analyze, that we become like beginners seeking to feel at ease with the task at hand" (Varela 1999, p. 18).

Likewise, Colombetti and Torrance (2009), the proponents of an (inter)- enactive approach to emotion and ethics, also have claimed that "No one should deny the importance of reason in ethics; nor indeed could there be any adequate account of emotions which did not take account of the ways in which emotions can be subject to various dimensions of rational scrutiny and criticism" (p. 515). ${ }^{9}$ However, as it has been mentioned by Hugo Mercier (2011), "while none of the scholars within the intuitionist framework deny that reasoning can play a positive role in our mental lives, its 'servile' function still plays a major part in their theorizing" (p. 132). This seems to be the case of enactivist theories as well.

\footnotetext{
8 The emphasis is mine.

${ }^{9}$ As it has been noted by Hindriks (2014), the western tradition of classical moral intuitionism shares these basic assumptions concerning the role of reasoning in moral psychology. Some of the proponents of moral intuitionism such as Sidwick (1874/1962), Moore (1903/1998), and Ross and Stratton-Lake (1930/2009), are examples of sort of rationalist account in moral intuitionism. According to these perspectives, moral intuitions require reflection, and moral intuitions are justified and warranted, since "...they are the intuitions of rational agents" (Hindriks 2014, p. 200).
} 
The perspective offered by the constructivist tradition has a lot to say about this issue. During development, human reasoning and deliberation become essential elements for the acquisition, consolidation, and revision of moral concerns, judgments, and principles of behavior. This is in line with a previous statement, namely, that communication and language are fundamental to constitute a normative stance in social interactions (Paulus 2020). As is explained by $\mathrm{Li}$ and Tomasello (2021), language facilitates all aspects of morality, including the initiation, preservation, revision, and materialization of moral judgments and actions. More importantly, language allows engaging in moral reasongiving, which is a central aspect of moral development. In brief, the essential role of communication and language in morality includes the processes of moral reasoning and moral deliberation.

It is essential to clarify that these processes (e.g., language, reasoning, and deliberation), are understood as forms of social action, this is, as dynamic processes of interaction between individuals (Di Paolo et al. 2018). In other words, when humans communicate through language, when we engage in processes of reason-giving, or when we deliberate, what is at play is between-mind interactions that require a socially externalist perspective to be explored, instead of a 'within minds' perspective (Li and Tomasello 2021).

Accordingly, human reasoning is conceived as a flexible and socially-contingent process of evaluation and elaboration of judgments and arguments (Piaget 1932/2013, 1977/2015; Kohlberg 1981, 1984; Habermas 2005; Dahl and Killen 2018b; Mammen et al. 2018, 2019; Killen and Dahl 2021). Moreover, moral reasoning is the process through which people initiate, preserve, revise, and realize evaluations and judgments based on concerns about others' welfare, rights, fairness, or justice (Dahl and Killen 2018b; Paulus 2020; Killen and Dahl 2021).

The relevance of reasoning and deliberation does not exclude whatsoever the fact that ethical expertise involves intuitive embodied judgments or the emergent realization of automatic and habitual patterns of behavior that are the outcome of an agent's situated perspective in her world. Many forms of moral reasoning may develop into intuitive and automatic patterns of behavior, which are fast, effortless, and instances of expertise (Pizarro and Bloom 2003; Turiel and Killen 2010; Dahl and Killen 2018b). Authors like Hogarth (2001), Pollard (2003, 2005), Snow (2006, 2010), and Sauer (2017) have recently contributed to the task of consolidating a non-dualistic perspective on the relation between automaticity and rationality such as the one here proposed. To sum up, from a constructivist perspective, intuition and reasoning are just two sides of a unique process of formation and education of moral concerns and judgments (Hindriks 2014; Sauer 2017).
Moral reasoning and deliberation depend on a background of moral evaluations and concerns that have an irreducible affective origin. These interactions between affective, cognitive, and linguistic dimensions in moral development may be reexamined with a brief look into psychological evidence. For instance, the basic relations between emotion and cognition are already evident from the very initial process of emotion elicitation. Contrary to what is assumed by most intuitionist perspectives in moral psychology, to which emotions seem to be inflexible reactions to environmental stimuli, emotions usually involve evaluative appraisals (Nussbaum 2003; Turiel and Killen 2010; Sauer 2017). Furthermore, the precursors of moral reasoning in the first years of life are emotional. As it has been noted by Dahl and Killen (2018a, b) and Ball et al. (2016), the very bases for the development of our moral concerns are emotional processes such as empathic responsiveness to distress, early social understanding, and moral emotions such as guilt and shame. These emotional processes constitute the background for moral reasoning and deliberation to occur in scenarios of cooperation and conflict.

Finally, the development of moral concerns, evaluations, judgments, and norms through social interactions, presents multiple challenges that are usually solved by the means of moral reasoning and deliberation. Moral concerns, judgments, and norms may conflict with other domains of social knowledge, and even they may conflict with each other. For instance, concerns for equality and fairness can be subordinated to considerations of group identity and parochial prosociality, and moral concerns for well-being might conflict with moral concerns for fairness (Turiel and Killen 2010). At this point, moral reasoning and deliberation acquire special relevance, since they foster more adequate ways to apply principles about welfare, justice, and rights, especially when they conflict with each other in contexts of extreme inequalities of power and influence between individuals. That's the reason why moral reasoning has been claimed to enable not only moral development but also societal change (Killen and Dahl 2021).

Consequently, the appeal to reasoning also has a philosophical justification. Normatively speaking, human reasoning is conceived as the process through which we reach 'better' or 'correct' moral judgments, these are judgments that are justifiable to all (Kohlberg 1981; Sauer 2017; Hindriks 2014; Hindriks and Sauer 2020). This makes reasoning a necessary element in the acquisition, education, and revision of adequate moral concerns, judgments, and principles, and moral rationalism a necessary stance towards the normative quality of our moral systems. 


\section{Conclusions}

To sum up, for humans to think morally in social environments it is necessary to develop a capacity to recognize morally relevant scenarios, to identify moral transgressions, to feel concerned about morally divergent issues, and to make judgments and decisions with morally relevant consequences. Our moral life involves the flexible application of moral principles since concerns about welfare, justice, and rights are sensitive and contingent on social and contextual factors. Moral motivation and reasoning are situated and embedded phenomena, and the result of a very complex developmental process.

In this paper, I have argued that embodied perspectives, enactivism included, face important challenges that result from their analysis of the social origins of human morality. My main objective has been to expand the horizon of conceptual, empirical, and descriptive implications that they need to address in the construction of a coherent ethical perspective. I have done so by exposing a constructivist approach to the social origins of human morality, taking insights from the cognitive-evolutionary tradition in moral psychology. This alternative radically eschews dichotomies to explain human moral behavior. Moreover, based on the constructivist definition of the moral domain of social knowledge, I have offered a basic notion of moral sensemaking and I have called attention to the relevance of distinguishing what makes the development of moral norms different from the development of other domains of social normativity.

Moreover, I have also explored the role of individuality and reasoned deliberation in the development and education of moral concerns, moral principles, and morally relevant norms of behavior. First, human morality demands the occurrence of factors that go beyond the simple automatic reaction to environmental stimuli or the conformity to concrete patterns of social normativity. That is why autonomous independent thinking and individuality are necessary factors for humans to "challenge group norms, authority, and institutional mandates" (Killen 2018, p. 769). Secondly, to define the moral domain as a set of concerns and evaluations about individual well-being (normative individualism) does not imply the adoption of an 'individualistic' picture about the acquisition of those moral considerations or the goals of society. Finally, I have claimed the relevance of rationality in the processes through which human individuals reach more equilibrated levels of consensus in social dilemmas and moral considerations. The appeal to reasoning does not exclude whatsoever the role of emotions, intuitions, social interactions, and expertise, as constituent components for the realization of our moral actions. All these reflections are fundamental since our moral domain sometimes requires, to be developed properly, an autonomous, deliberate, and reasoned reaction to the general normativity that sustains the social life of communities.

Funding Open Access funding enabled and organized by Projekt DEAL. This work received support from Deutscher Akademischer Austauschdienst (Grant No. 91686400).

Open Access This article is licensed under a Creative Commons Attribution 4.0 International License, which permits use, sharing, adaptation, distribution and reproduction in any medium or format, as long as you give appropriate credit to the original author(s) and the source, provide a link to the Creative Commons licence, and indicate if changes were made. The images or other third party material in this article are included in the article's Creative Commons licence, unless indicated otherwise in a credit line to the material. If material is not included in the article's Creative Commons licence and your intended use is not permitted by statutory regulation or exceeds the permitted use, you will need to obtain permission directly from the copyright holder. To view a copy of this licence, visit http://creativecommons.org/licenses/by/4.0/.

\section{References}

Asma ST, Gabriel R (2019) The emotional mind: the affective roots of culture and cognition. Harvard University Press, Cambridge

Bagnoli C (2016) Kantian constructivism and the moral problem. Philosophia 44(4):1229-1246. https://doi.org/10.1007/ s11406-016-9745-4

Ball CL, Smetana JG, Sturge-Apple ML (2016) Following my head and my heart: integrating preschoolers' empathy, theory of mind, and moral judgments. Child Dev 88(2):597-611. https:// doi.org/10.1111/cdev.12605

Bandura A, McDonald FJ (1963) Influence of social reinforcement and the behavior of models in shaping children's moral judgment. J Abnormal Soc Psychol 67(3):274

Beitz CR (1999) Political theory and international relations. Princeton University Press

Bergmann LT, Wagner J (2020) When push comes to shove-the moral fiction of reason-based situational control and the embodied nature of judgment. Front Psychol. https://doi.org/ 10.3389/fpsyg.2020.00203

Bloom P (2013) Just babies: the origins of good and evil. Broadway Books, New York

Brownell CA, Early Social Development Research Lab (2016) Prosocial behavior in infancy: the role of socialization. Child Dev Perspect 10(4):222-227

Buchanan A, Powell R (2018) The evolution of moral progress: a biocultural theory. Oxford University Press, Oxford

Carpendale JIM (2009) Piaget's theory of moral development. In: Müller U, Carpendale JIM, Smith L (eds) Cambridge companion to Piaget. Cambridge University Press, New York, pp 270-286

Carpendale JIM, Hammond SI (2016) The development of moral sense and moral thinking. Curr Opin Pediatr 28(6):743-747. https://doi.org/10.1097/mop.0000000000000412

Carpendale J, Lewis C (2010) The development of social understanding: a relational perspective. In: Overton W (ed) Handbook of lifespan developmental psychology. Wiley, New York, pp $584-627$ 
Carpendale JIM, Hammond SI, Atwood S (2013) A relational developmental systems approach to moral development. Adv Child Dev Behav 45:125-153

Chemero A (2011) Radical embodied cognitive science. MIT Press, Cambridge

Colombetti G (2010) Enaction, sense-making, and emotion. In: Gapenne SJ, Di Paolo E (eds) Enaction: toward a new paradigm for cognitive science. MIT Press, Cambridge, pp 145-164

Colombetti G (2014) The feeling body: affective science meets the enactive mind. MIT press, Cambridge

Colombetti G (2017) The feeling body: affective science meets the enactive mind. The MIT Press, Cambridge, London

Colombetti G, Torrance S (2009) Emotion and ethics: an inter-(en) active approach. Phenomenol Cogn Sci 8(4):505-526. https:// doi.org/10.1007/s11097-009-9137-3

Dahl A (2016) Mothers' insistence when prohibiting infants from harming others in everyday interactions. Front Psychol 7:1448

Dahl A (2019) The science of early moral development: on defining, constructing, and studying morality from birth. Adv Child Dev Behav 56:1-35

Dahl A, Brownell CA (2019) The social origins of human prosociality. Curr Dir Psychol Sci 28(3):274-279

Dahl A, Campos JJ (2013) Domain differences in early social interactions. Child Dev 84(3):817-825

Dahl A, Freda GF (2017) How young children come to view harming others as wrong: a developmental analysis. In: Sommerville JA, Decety J (eds) Social cognition. Routledge, New York, pp 151-184

Dahl A, Killen M (2018a) A developmental perspective on the origins of morality in infancy and early childhood. Front Psychol. https://doi.org/10.3389/fpsyg.2018.01736

Dahl A, Killen M (2018b) Moral reasoning: theory and research in developmental science. Stevens' Handbook of Exp Psychol Cogn Neurosci 4:1-31

Dahl A, Kim L (2014) Why is it bad to make a mess? Preschoolers' conceptions of pragmatic norms. Cogn Dev 32:12-22

Dahl A, Paulus M (2018) From interest to obligation: the gradual development of human altruism. Child Dev Perspect 13(1):10-14. https://doi.org/10.1111/cdep.12298

Dahl A, Campos JJ, Witherington DC (2011) Emotional action and communication in early moral development. Emot Rev $3(2): 147-157$

Dahl A, Waltzer T, Gross RL (2017) Helping, hitting, and developing: toward a constructivist-interactionist account of early morality. In: Helwig CC (ed) New perspectives on moral development. Routledge, New York, pp 33-54

Damon W (1977) The social world of the child. Jossey-Bass Publishers, San Francisco

Day JM, Tappan MB (1996) The narrative approach to moral development: From the epistemic subject to dialogical selves. Human Dev 39(2):67-82

De Jaegher H (2013) Rigid and fluid interactions with institutions. Cogn Syst Res 25-26:19-25. https://doi.org/10.1016/j.cogsys. 2013.03.002

De Jaegher H, Di Paolo E (2007) Participatory sense-making. Phenomenol Cogn Sci 6(4):485-507. https://doi.org/10.1007/ s11097-007-9076-9

Di Paolo EA, Cuffari EC, De Jaegher H (2018) Linguistic bodies: the continuity between life and language. MIT Press, Cambridge

Dreyfus HL, Dreyfus SE (1991) Towards a phenomenology of ethical expertise. Hum Stud 14(4):229-250. https://doi.org/10.1007/ bf02205607

Gigerenzer G (2008) Gut feelings: the intelligence of the unconscious. Penguin Books, New York
Gilligan C (1982/2006) In a different voice: psychological theory and women's development. Harvard University Press, Cambridge

Gordon DB, Tetsuro W, Seisaku Y, Carter RE (1999) Watsuji Tetsuro's Rinrigaku: ethics in Japan. Philosophy East West 49(2):216. https://doi.org/10.2307/1400208

Graham J, Haidt J, Koleva S, Motyl M, Iyer R, Wojcik SP, Ditto PH (2013) Moral foundations theory: the pragmatic validity of moral pluralism. In: Devine P, Plant A (eds) Advances in experimental social psychology, vol 47. Academic Press, Burlington, pp $55-130$

Greene JD (2001) An fMRI investigation of emotional engagement in moral judgment. Science 293(5537):2105-2108. https://doi.org/ $10.1126 /$ science. 1062872

Greene JD (2007) Why are VMPFC patients more utilitarian? A dualprocess theory of moral judgment explains. Trends Cogn Sci 11(8):322-323. https://doi.org/10.1016/j.tics.2007.06.004

Grusec JE, Chaparro MP, Johnston M, Sherman A (2014) The development of moral behavior from a socialization perspective. In M. Killen \& J. G. Smetana (Eds.), Handbook of moral development (pp. 113-134). Psychology Press

Habermas J (2005) Justification and application: remarks on discourse ethics. Polity, Cambridge

Haidt J (2001) The emotional dog and its rational tail: a social intuitionist approach to moral judgment. Psychol Rev 108(4):814834. https://doi.org/10.1037/0033-295x.108.4.814

Haidt J (2013) The righteous mind: why good people are divided by politics and religion. Penguin Books, London

Haidt J, Bjorklund F (2008) Social intuitionists answer six questions about moral psychology. In: Sinnott-Armstrong W (ed) Moral psychology, Vol 2: the cognitive science of morality intuition and diversity. MIT Press, Cambridge, pp 181-217

Hamlin JK (2013) Moral judgment and action in preverbal infants and toddlers: evidence for an innate moral core. Curr Dir Psychol Sci 22(3): 186-193

Hamlin JK, Wynn K, Bloom P (2007) Social evaluation by preverbal infants. Nature 450(7169):557-559

Hardecker S, Schmidt MF, Roden M, Tomasello M (2016) Young children's behavioral and emotional responses to different social norm violations. J Exp Child Psychol 150:364-379

Held V (2007) The ethics of care: personal, political, and global. Oxford University Press, New York

Hindriks F (2014) Intuitions, rationalizations, and justification: a defense of sentimental rationalism. J Value Inq 48(2):195-216. https://doi.org/10.1007/s10790-014-9419-z

Hindriks F, Sauer H (2020) The mark of the moral: beyond the sentimentalist turn. Philos Psychol. https://doi.org/10.1080/09515 089.2020 .1731444

Hogarth RM (2001) Educating intuition. University Of Chicago Press, Chicago

Hutcheson F (2014) A system of moral philosophy/1. Cambridge University Press, Cambridge

Jambon M, Smetana JG (2014) Moral complexity in middle childhood: children's evaluations of necessary harm. Dev Psychol 50(1):22-33. https://doi.org/10.1037/a0032992

Jones C (1999) Global justice: Defending cosmopolitanism. Oxford: Oxford University Press

Killen M (2018) The origins of morality: social equality, fairness, and justice. Philos Psychol 31(5):767-803. https://doi.org/10.1080/ 09515089.2018.1486612

Killen M, Dahl A (2021) Moral reasoning enables developmental and societal change. Perspect Psychol Sci. https://doi.org/10.1177/ 1745691620964076

Kochanska G (1993) Toward a synthesis of parental socialization and child temperament in early development of conscience. Child Dev 64(2):325-347 
Kohlberg L (1981) Essays on moral development/1: the philosophy of moral development: moral stages and the idea of justice. Harper \& Row, San Francisco

Kohlberg L (1984) Psychology of moral development: nature and validity of moral stages. Harper \& Row, San Francisco

Korsgaard CM (2003) Realism and constructivism in twentieth-century moral philosophy. J Philos Res 28(9999):99-122. https://doi.org/ $10.5840 /$ jpr_2003_8

Li L, Tomasello M (2021) On the moral functions of language. Soc Cogn 39(1):99-116

Loaiza JM (2019) From enactive concern to care in social life: towards an enactive anthropology of caring. Adapt Behav 27(1):17-30

Macintyre AC (1981/2014) After virtue: a study in moral theory. Bloomsbury, London

Mammen M, Köymen B, Tomasello M (2018) The reasons young children give to peers when explaining their judgments of moral and conventional rules. Dev Psychol 54(2):254-262. https://doi.org/ $10.1037 /$ dev0000424

Mammen M, Domberg A, and Köymen B. (2019). Reasoning in communication. The encyclopedia of child and adolescent development, $1-8$

Mascolo MF, Fasoli AD (2020) The relational origins of morality and its development. In: Mascolo MF, Bidell TR (eds) Handbook of integrative developmental science essays in honor of Kurt W. Fischer. Routledge, New York

McCarthy E (2010) Ethics embodied: rethinking selfhood through continental, Japanese, and feminist philosophies. Lexington Books, Lanham

Mercier H (2011) What good is moral reasoning? Mind Soc 10(2):131148. https://doi.org/10.1007/s11299-011-0085-6

Métais F, Villalobos M (2021) Embodied ethics: Levinas' gift for enactivism. Phenomenol Cogn Sci 20(1):169-190

Moore GE (1998) Principia Ethica. Presses Universitaires De France, Editorial Paris

Noddings N (2013) Caring: a relational approach to ethics and moral education. University of California Press, Oakland

Nucci L (2016) Recovering the role of reasoning in moral education to address inequity and social justice. J Moral Educ 45(3):291-307. https://doi.org/10.1080/03057240.2016.1167027

Nussbaum MC (2003) Upheavals of thought: the intelligence of emotions. Cambridge University Press, Cambridge

Paulus M (2014) The emergence of prosocial behavior: why do infants and toddlers help, comfort, and share? Child Dev Perspect $8(2): 77-81$

Paulus, M. (2020). How do young children become moral agents? A developmental perspective. In: Decety, J (Ed.) The Social Brain: A Developmental Perspective (pp. 161-177). The MIT Press

Piaget J (1932/2013) The moral judgment of the child. Harcourt, Brace, And Company, New York

Piaget J (1977/2011) Sociological studies. Routledge, London

Pizarro DA, Bloom P (2003) The intelligence of the moral intuitions: comment on Haidt (2001). Psychol Rev 110:193-196

Pletti C, Scheel A, Paulus M (2017) Intrinsic altruism or social motivation-what does pupil dilation tell us about children's helping behavior? Front Psychol. https://doi.org/10.3389/fpsyg.2017. 02089

Pollard B (2003) Can virtuous actions be both habitual and rational? Ethical Theory Moral Pract 6(4):411-425

Pollard B (2005) Naturalizing the space of reasons. Int J Philos Stud 13(1):69-82

Prinz J (2006) The emotional basis of moral judgments. Philos Explor 9(1):29-43. https://doi.org/10.1080/13869790500492466

Prinz JJ (2007) The emotional construction of morals. Oxford University Press, Oxford

Rawls J (1980) Kantian constructivism in moral theory. J Philos 77(9):515-572. https://doi.org/10.2307/2025790
Ross WD, Stratton-Lake P (2009) Right and the good. Clarendon Press, Oxford

Sauer H (2017) Moral judgments as educated intuitions. The MIT Press, Cambridge, London

Scanlon T (1998) What we owe to each other. Harvard University Press, Cambridge

Shapiro LA (2019) Embodied cognition. Routledge, London

Shun KL, Wong DB (Eds.) (2004) Confucian ethics: A comparative study of self, autonomy, and community. Cambridge University Press

Shweder RA (1982) Liberalism as destiny [review of the book the philosophy of moral development: moral stages and the idea of justice, vol. 1. Essays on moral development, by L. Kohlberg. Contemp Psychol 27(6):421-424. https://doi.org/10.1037/021204

Shweder RA, Much NC, Mahapatra M, Park L (1997) The "big three" of morality (autonomy, community, divinity) and the "big three" explanations of suffering. Morality and Health 119:119-169

Sidgwick H (1962) The methods of ethics. Macmillan, London

Smetana JG (1984) Toddlers' social interactions regarding moral and conventional transgressions. Child Dev 55(5):1767. https://doi. org/10.2307/1129924

Smetana JG (1989) Toddlers' social interactions in the context of moral and conventional transgressions in the home. Dev Psychol 25(4):499-508. https://doi.org/10.1037/0012-1649.25.4.499

Smetana JG, Braeges JL (1990) The development of toddlers' moral and conventional judgments. Merrill-Palmer Q 36:329-346

Smetana JG, Jambon M, Ball CL (2018) Normative changes and individual differences in early moral judgments: a constructivist developmental perspective. Hum Dev 61(4-5):264-280. https:// doi.org/10.1159/000492803

Smith A (2010) The theory of moral sentiments. Penguin, London

Snow NE (2006) Habitual virtuous actions and automaticity. Ethic Theory Moral Pract 9(5):545-561

Snow NE (2010) Virtue as social intelligence: an empirically grounded theory. Routledge, Oxfordshire

Stewart J, Gapenne O, Di Paolo E (2014) Enaction: toward a new paradigm for cognitive science. The MIT Press, Cambridge

Street S (2010) What is constructivism in ethics and metaethics? Philos Compass 5(5):363-384. https://doi.org/10.1111/j.1747-9991. 2009.00280.x

Taylor C (1989) Sources of the self: the making of the modern identity. Harvard University Press, Cambridge

Thompson E (2010) Mind in life: biology, phenomenology, and the sciences of mind. The Belknap Press of Harvard University Press, Cambridge

Tomasello M (2018) A natural history of human thinking. Harvard University Press, Cambridge

Tomasello M, Gonzalez-Cabrera I (2017) The role of ontogeny in the evolution of human cooperation. Hum Nat 28(3):274-288. https://doi.org/10.1007/s12110-017-9291-1

Tronto JC (1993) Moral boundaries: a political argument for an ethic of care. Psychology Press, Hove

Turiel E (1985) The development of social knowledge: morality and convention. Cambridge University Press, Cambridge

Turiel E (2015) Moral development. In: Lerner RM (ed) Handbook of child psychology and developmental science, vol 1. Wiley, New York, pp 484-522

Turiel E, Dahl A (eds) (2019) The development of domains of moral and conventional norms, coordination in decision-making, and the implications of social opposition. The normative animal? Oxford University Press, Oxford, pp 195-213

Turiel E, Killen M (2010) Taking emotions seriously: the role of emotions in moral development. In: Arsenio W, Lemerise EA (eds) Emotions, aggression, and morality in children: bridging development and psychopathology. American Psychological Association Press, Washington, pp 33-52 
Urban P (2014) Toward an expansion of enactive ethics with the help of care ethics. Front Psychol. https://doi.org/10.3389/fpsyg.2014. 01354

Urban P (2015) Enacting care. Ethics and Social Welfare 9(2):216-222. https://doi.org/10.1080/17496535.2015.1022356

van Grunsven J (2018) Enactivism, second-person engagement, and personal responsibility. Phenomenol Cogn Sci 17(1):131-156. https://doi.org/10.1007/s11097-017-9500-8

Varela FJ (1999) Ethical know-how: action, wisdom, and cognition. Stanford University Press, Stanford

Varela FJ, Rosch E, Thompson E (2016) The embodied mind: cognitive science and human experience. The MIT Press, Cambridge

Wainryb C, Recchia H (2017) Mother-child conversations about children's moral wrongdoing: A constructivist perspective on moral socialization. In: Budwig, N., Turiel, E., \& Zelazo, P.D. (Eds). New perspectives on human development: Rethinking cognitive, social, and language \& communicative development (pp. 182-208). Cambridge University Press
Warneken F, Tomasello M (2007) Helping and cooperation at 14 months of age. Infancy 11(3):271-294. https://doi.org/10.1111/j. 1532-7078.2007.tb00227.x

Yearley LH (1990) Mencius and Aquinas: Theories of virtue and conceptions of courage. Suny Press

Yucel M, Hepach R, Vaish A (2020) Young children and adults show differential arousal to moral and conventional transgressions. Front Psychol. https://doi.org/10.3389/fpsyg.2020.00548

Zahn-Waxler C, Radke-Yarrow M, Wagner E, Chapman M (1992) Development of concern for others. Dev Psychol 28(1):126

Publisher's Note Springer Nature remains neutral with regard to jurisdictional claims in published maps and institutional affiliations. 